\title{
Renal replacement therapy in intensive care units in KwaZulu-Natal Province, South Africa
}

\author{
D L Skinner, ${ }^{1}$ MB ChB, FCS (SA), MMed (Surg), Cert Critical Care (SA); OrcID 0000-0002-2769-2436; \\ K de Vasconcellos, ${ }^{1}$ MB ChB, FCA (SA), Cert Critical Care (SA), MMedSci; OrcID 000-0002-1974-6633; \\ R Wise, ${ }^{1,2}$ MB ChB, FCA (SA), Cert Critical Care (SA), MMed (Anaes); OrcID 0000-0001-5237-5582; \\ T Kisten, ${ }^{1}$ MB ChB, DA (SA), FCA (SA), Cert Critical Care (SA), MMed; OrcID 0000-0002-1609-6962; \\ M Faurie, ${ }^{3}$ BSc, MB ChB, MMed (Surg), FCS (SA), Cert Trauma (SA); OrcID; \\ T Hardcastle, ${ }^{3,4}$ MB ChB, MMed (Chir), FCS (SA), Trauma Surgery, PhD; OrcID 0000-0002-3967-0234; \\ D J J Muckart, ${ }^{3}$ FRCS, MMSc, Cert Crit Care (SA)
}

\author{
${ }^{1}$ Department of Anaesthesiology and Critical Care, Nelson Mandela School of Medicine, School of Clinical Medicine, University of KwaZulu-Natal, \\ Durban, South Africa \\ ${ }^{2}$ Department of Intensive Care, John Radcliffe Hospital, Oxford University Hospitals NHS Foundation Trust, Oxford, United Kingdom \\ ${ }^{3}$ Department of Surgery, Nelson R Mandela School of Medicine, School of Clinical Medicine, University of KwaZulu-Natal, Durban, South Africa \\ ${ }^{4}$ Trauma Service, KwaZulu-Natal Department of Health, Durban, South Africa
}

Corresponding author: D L Skinner(dave@criticalcareconsulting.co.za)

\begin{abstract}
Background. Renal replacement therapy (RRT) is a scarce resource in southern Africa. Critically ill patients are at risk of developing acute kidney injury (AKI), which may require RRT. There are few data on the utilisation of RRT in southern African intensive care units (ICUs).

Objectives. To determine the indications for initiating RRT in critically ill patients in ICUs in KwaZulu-Natal, South Africa (SA) and to describe the methods and dosing of RRT.

Methods. A prospective observational study was performed to investigate the indications for initiating, methods and dosing of RRT among patients admitted to four ICUs in KwaZulu-Natal Province, SA. All adult patients were eligible for inclusion.

Results. A total of 108 patients who received RRT were included in the study. The most common reasons for initiation of RRT were a high/rising creatinine, high/rising urea, acidosis and fluid balance. The majority of the patients $(79.6 \% ; n=86)$ had three or more indications for RRT. A total of 353 intermittent haemodialysis/slow low-efficiency dialysis (IHD/SLED) sessions and 84 continuous renal replacement therapy (CRRT) sessions were recorded. The median (interquartile range (IQR)) CRRT dose was $25.8(19.1-28.8) \mathrm{mL} / \mathrm{kg} / \mathrm{h}$. The median (IQR) urea reduction ratio for IHD/SLED was $32.4 \%$ (15.0 - 49.8).

Conclusion. Patients in this study had multiple indications for initiating RRT. The dosing of RRT was not optimal, with a wide range shown in CRRT, and the majority of patients did not achieve a urea reduction ratio (URR) $>65 \%$.

Keywords. renal replacement therapy; dialysis; blood purification; acute kidney injury; critical care.
\end{abstract}

South Afr J Crit Care 2021;37(1):21-26. https://doi.org/10.7196/SAJCC.2021.v37i1.454

Contribution of the study. Renal replacement therapy is a scarce resource in Africa. Little is known about the current types and dosing of RRT in critical care units in South Africa. We showed that critically ill patients had multiple indications for RRT and the dosing was not optimal.

Renal replacement therapy (RRT) is a scarce and expensive resource in developing countries. ${ }^{[1-3]}$ Critically ill patients in developing countries are at risk for acute kidney injury (AKI) with rhabdomyolysis, sepsis, toxin ingestion or severe metabolic acidosis being common requests for intensive care admission for RRT. ${ }^{[3-6]}$ In South African (SA) intensive care units (ICUs), RRT is commonly undertaken by both intensivists and nephrologists in the ICUs. ${ }^{[4,5]}$

The relative scarcity of RRT in developing countries places a burden on clinicians that have access to this modality of treatment. The need for RRT in patients with acute indications for haemodialysis or ultrafiltration often has to be weighed against the availability of dialysis machines. ${ }^{[3]}$ This difficulty in triage of scarce resources in SA has previously been tested legally in a patient with chronic kidney disease (CKD) ${ }^{[7]}$
Currently, there is no consensus regarding the criteria for the initiation of RRT. There are often multiple reasons, but the indications for type and dose of RRT in SA require further investigation. ${ }^{[4]}$ Our study aimed to examine the utilisation of RRT in ICUs capable of RRT in KwaZuluNatal (KZN) Province, SA. We analysed the demographics of patients who received RRT, indications for RRT and outcomes (length of stay (LoS), length of ventilation (LoV) and ICU mortality).

\section{Methods}

A prospective observational study was performed to investigate the utilisation of RRT among patients admitted to ICUs in KwaZuluNatal with respect to indications for initiation, methods and dosing of RRT. 
The primary outcome of the study was to determine the indications for initiating RRT in critically ill patients in ICUs in KwaZulu-Natal. The secondary objectives were to describe the methods of RRT offered to patients and dosing of these methods. The outcomes of patients that received RRT were evaluated in terms of ICU mortality, length of ventilation (LoV), length of ICU stay (LoS) and renal recovery in the ICU as defined by no longer requiring RRT.

Initially, only one ICU was involved in the study but due to slow enrolment, three other ICUs were involved in patient recruitment. The initial time of enrolment was from 01 January 2017 and other ICUs were included in patient recruitment from 01 October 2017. The study inclusion period ended on 28 February 2018. Ethics permission was obtained from the Biomedical Research Ethics Committee of the University of KwaZuluNatal (ref. no. BE400/16), the KwaZulu-Natal Health Research Committee, and the hospital gatekeepers, respectively. The need for consent was waived as this was a prospective non-interventional observational study.

The kidney diseases improving global outcomes (KDIGO) definitions and staging of AKI (Table 1) were applied using serum creatinine values and the modification of disease in renal diet (MDRD) equation for calculation of a patient's baseline creatinine levels if the baseline value was unknown. ${ }^{[8]}$

The types of RRT evaluated were continuous RRT (CRRT) in the form of veno-venous haemodiafiltration and slow low-efficiency dialysis (SLED)/intermittent haemodialysis (IHD). In the present study, SLED was defined as any haemodialysis session lasting $>8$ and $<24$ hours, while IHD was defined as any haemodialysis session lasting $\leq 8$ hours. The two latter forms of RRT were grouped together for analysis purposes.

Dosing of RRT was used as effluent flow rate for CRRT in $\mathrm{mL} / \mathrm{kg} / \mathrm{h}$ and a urea reduction ratio (URR) for IHD/SLED RRT. Adequacy of dosing for CRRT was defined as $20-25 \mathrm{~mL} / \mathrm{kg} / \mathrm{h}^{[8]}$ and a URR of $\geq 65 \%$ for IHD/ SLED ${ }^{[8,9]}$

\section{Statistical analysis}

Means and standard deviations (SDs) are reported for normally distributed data, and median and interquartile range (IQR) for data that are not normally distributed. The $\chi^{2}$ test and Fisher's exact test were used for categorical data, and independent samples $t$-test, Kruskall-Wallis, or Mann-Whitney $U$-test for continuous data where appropriate. Statistical significance was defined as a two-sided $p<0.05$. All data analyses were performed using SPSS version 24.0 (IBM Corp., USA).

\section{Study setting}

Four ICU's in KwaZulu-Natal Province, SA, were included in the study. All ICUs are 'closed' (intensivist with consultation with other disciplines) and the management of RRT is undertaken within the unit by the intensive care team consisting of specialist intensivists and trainees independent of nephrologists.

\begin{tabular}{|c|c|c|}
\hline Stage & SCr criteria & Urine output criteria \\
\hline 1 & $\begin{array}{l}\text { SCr increase } \geq 50 \% \text { in } 7 \text { days } \\
\text { or } \geq 0.3 \mathrm{mg} / \mathrm{dL} / 26.5 \mathrm{mmol} / \mathrm{L} \\
\text { within } 48 \mathrm{~h}\end{array}$ & $<0.5 \mathrm{~mL} / \mathrm{kg} / \mathrm{h}$ for $6-12 \mathrm{~h}$ \\
\hline 2 & SCr increase $\geq 100 \%$ & $<0.5 \mathrm{~mL} / \mathrm{kg} / \mathrm{h}$ for $\geq 12 \mathrm{~h}$ \\
\hline 3 & $\begin{array}{l}\text { SCr increase } \geq 200 \% \text { or } \\
\geq 4 \mathrm{mg} / \mathrm{dL} \text { or need for RRT }\end{array}$ & $\begin{array}{l}<0.3 \mathrm{~mL} / \mathrm{kg} / \mathrm{h} \text { for } \geq 24 \mathrm{~h} \text { or } \\
\text { anuria for } 12 \mathrm{~h}\end{array}$ \\
\hline
\end{tabular}

Edendale hospital ICU is a 6-bed unit and admits a mix of patients from specialty units in surgery (both trauma and non-trauma), general medicine, and obstetrics and gynaecology. The unit has 1 dialysis machine capable of SLED/IHD.

King Edward VIII Hospital (KEH) ICU is a 12-bed unit and has 2 dialysis machines capable of IHD/SLED and 1 machine capable of CRRT. The unit is also a general specialty ICU. Patients who were deemed haemodynamically unstable were started on CRRT and changed to SLED/IHD once haemodynamically stable.

The trauma ICU is an 8-bed unit in Inkosi Albert Luthuli Central Hospital (IALCH) and admits critically ill trauma patients from around the province with 2 dialysis machines capable of SLED/IHD with no capability for CRRT.

The surgical ICU at IALCH is a 6-bed unit and admits a mix of patients similar to Edendale and KEH ICUs, exclusive of trauma surgery. The unit uses CRRT on any patient requiring RRT that is haemodynamically unstable and IHD/SLED for more stable patients.

All patients admitted to the ICUs during the study period were eligible for inclusion. Patients who did not receive RRT, patients who received peritoneal dialysis only, children under the age of 18 years, patients accepted but died prior to admission to the ICU and patients who died within 6 hours of admission were excluded from the study.

The dialysis machines used in the various units for IHD/SLED were Braun Dialog+, Braun Adimea Evolution (Braun, Germany) and Fresenius Medical Care 4008S (Fresenius, Germany). Gambro Prismaflex (Gambro, Germany) and Braun Diapact (Braun, Germany) machines were utilised for CRRT.

For CRRT sessions, the effluent rate was calculated per session and the dose reported in $\mathrm{mL} / \mathrm{kg} / \mathrm{hr}$. The time of each CRRT was recorded from initiation of the RRT, accounting for interruptions for circuit clotting and filter change until the decision to discontinue the CRRT was made and enacted. Urea reduction rate (URR) was calculated using the formula (pre-RRT urea - post-RRT urea)/pre-RRT urea and reported for each IHD/SLED session and the median URR per patient that received IHD/SLED. ${ }^{[9]}$

Patient weights were either taken directly from a bed scale if available or estimated by the attending intensivist.

\section{Results}

We recruited 108 patients into the study. We recruited seven (6.5\%) patients from Edendale, 15 (13.9\%) from IALCH ICU, 58 (53.7\%) from KEH ICU and 28 (25.9\%) from IALCH Trauma ICU. The demographics of the patients are presented in Table 2.

Nineteen patients were admitted with no AKI, 19 were graded as stage 1 , eight as stage 2 and 62 as stage 3 . All patients received a stage 3 diagnosis as per KDIGO definition due to the use of RRT. If omitting the dialysis criterion for AKI staging and only using the serum creatinine for staging, 95 patients reached stage 3 , seven patientsreached stage 2 , two patients reached stage 1 and four patients did not reach staging criteria for AKI. Those four patients were all dialysed for toxin removal from drug overdose. The admission causes of AKI are listed in Table 3.

Admission biochemistry for all patients are presented in Table 4 . Patients received either CRRT, IHD, SLED or a combination of these 3 methods during their ICU stay. There were 85 sessions of CRRT prescribed and 353 sessions of IHD/SLED. IHD was the sole modality in $63 \%$ of patients, CRRT in $23 \%$ and both IHD and CRRT were utilised in $14 \%$ of patients. 
Table 2. Demographics of patients who received renal replacement therapy $(N=108)$

\begin{tabular}{ll}
\hline Characteristics & $\boldsymbol{n}(\%)^{\star}$ \\
\hline Male & $63(58.3)$ \\
Age (years), median (IQR) & $34(26-48)$ \\
Admission pathology & \\
$\quad$ Trauma & $42(38.9)$ \\
Medical & $30(27.8)$ \\
Surgical (non-trauma) & $28(25.9)$ \\
$\quad$ Obstetrics \& gynaecology & $8(7.4)$ \\
Comorbidities & \\
HIV infection & $27(25)$ \\
Hypertension & $21(19.4)$ \\
$\quad$ Chronic kidney disease & $16(14.8)$ \\
$\quad$ Diabetes mellitus & $13(12)$ \\
Previous RRT & \\
Intermittent haemodialysis & $16(14.8)$ \\
Peritoneal dialysis & $6(5.6)$ \\
Sepsis & $52(48.1)$ \\
& \\
IQR $=$ interquartile range; RRT = renal replacement therapy. & \\
${ }^{*}$ Unless otherwise specified. &
\end{tabular}

Table 3. Causes of AKI on admission to ICU $(N=108)^{*}$

\begin{tabular}{ll}
\hline Cause & $\boldsymbol{n}(\%)$ \\
\hline Sepsis & $32(29.6)$ \\
Crush injury & $17(15.7)$ \\
Blunt trauma & $15(13.9)$ \\
Penetrating trauma & $11(10.2)$ \\
Poisoning/toxins & $10(9.2)$ \\
Hypovolaemic shock (non-trauma) & $8(7.4)$ \\
Other (snake bite, multiple myeloma, eclampsia, & $15(13.9)$ \\
HIVAN, pancreatitis) & \\
AKI = acute kidney injury; HIVAN = human immunodeficiency virus-associated \\
nephropathy. \\
${ }^{*}$ Some patients developed multiple causes of AKI after admission to the ICU (e.g. sepsis).
\end{tabular}

The indications for initiating RRT are presented in Table 5. More than two-thirds $(79.6 \% ; n=86)$ of the patients had three or more indications for RRT (Fig. 1).

\section{Dosing of RRT}

We were unable to calculate the dose of one CRRT session due to missing information on effluent amount. Nine IHD/SLED sessions had incomplete data entered for calculation of URR.

The median (IQR) CRRT dose was 25.8 (19.1 - 28.8) mL/kg/h, with a range of $13.8-77.3 \mathrm{~mL} / \mathrm{kg} / \mathrm{h}$. The median (IQR) CRRT duration was $1440(840$ - 2 340) minutes, with a range of 140 - 9780 minutes. The dose range in quintiles is presented in Fig. 1. More than onequarter $(27.7 \%$; $n=23)$ of all CRRT sessions were dosed $<20 \mathrm{~mL} / \mathrm{kg} / \mathrm{h}$ (Fig. 2).

The median (IQR) URR was $32.4 \%$ (15.0 - 49.8). Three-quarters (75.3\%; $n=259$ ) of all IHD/SLED sessions had URR < $50 \%$ (Figs 3 and 4 ). The median (IQR) duration of IHD/SLED was 360 (360 - 360) minutes, with a minimum to maximum range of 120 - 600 minutes.

\section{Nephrotoxin administration}

The majority of the patients (44\%) received a potential nephrotoxin predialysis, which dropped to $22.2 \%$ post dialysis (Table 6).

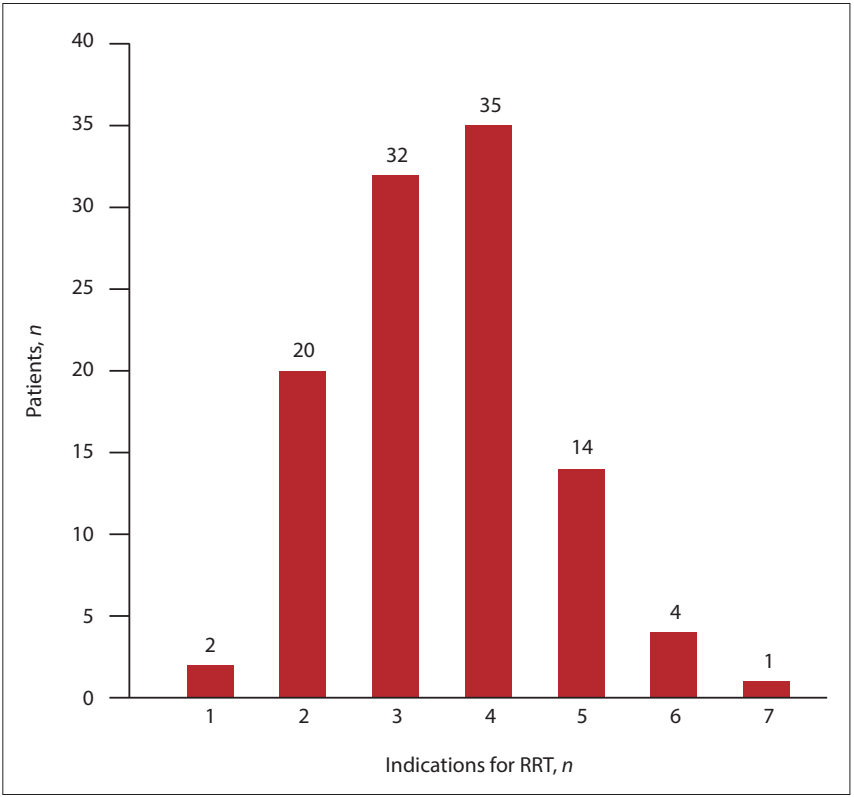

Fig. 1. Number of patients per indication for RRT. $(R R T=$ renal replacement therapy.)

Table 4. Admission biochemistry for all patients $(N=108)$

\begin{tabular}{ll}
\hline & Median $(\mathrm{IQR})$ \\
\hline $\mathrm{Hb}(\mathrm{g} / \mathrm{dL})$ & $9(7.5-11.3)$ \\
$\mathrm{BE}(\mathrm{mmol} / \mathrm{L})$ & $-9(-3.55--15.8)$ \\
$\mathrm{Na}(\mathrm{mmol} / \mathrm{L})$ & $137(134-141)$ \\
$\mathrm{K}(\mathrm{mmol} / \mathrm{L})$ & $4.8(3.9-5.8)$ \\
$\mathrm{Cl}(\mathrm{mmol} / \mathrm{L})$ & $105(101-108)$ \\
Urea & $19.1(8.5-30.925)$ \\
Admission creatinine $(\mathrm{mmol} / \mathrm{L})$ & $422.5(169.5-725.75)$ \\
Highest creatinine $(\mathrm{mmol} / \mathrm{L})$ & $580.5(414.75-813.00)$ \\
IQR = interquartile range; $\mathrm{Hb}=$ haemoglobin; $\mathrm{BE}=$ base excess; $\mathrm{Na}=$ sodium; \\
$\mathrm{K}=$ potassium; $\mathrm{Cl}=$ chloride.
\end{tabular}

Table 5. Indications for initiating RRT $(N=108)^{*}$

\begin{tabular}{ll}
\hline Indication & $\boldsymbol{n}(\%)$ \\
\hline High/rising creatinine & $86(79.6)$ \\
High/rising urea & $81(75.0)$ \\
Acidosis & $54(50.0)$ \\
Fluid balance & $42(38.9)$ \\
Anuria & $38(35.2)$ \\
Electrolyte abnormalities & $35(32.4)$ \\
Pulmonary oedema & $30(27.8)$ \\
Toxin & $10(9.3)$ \\
Other & $3(2.7)$ \\
& \\
& More than one indication was used for initiation of RRT.
\end{tabular}

\section{Outcomes}

Crude mortality in ICU was $37.0 \%(n=40 / 108)$. Life-sustaining therapy was considered futile for the majority of the patients $(77.5 \% ; n=31 / 40)$ who died in the ICU. The median (IQR) LoS and LoV was 9 (5 - 15) days and $6(3-10)$ days, respectively. Out of the 68 patients who were discharged alive, $63.2 \%(n=43)$ either had no further need for RRT or renal recovery from AKI did not require RRT. The 25 patients requiring RRT on discharge were referred to the relevant medical/ nephrology services for ongoing RRT. 


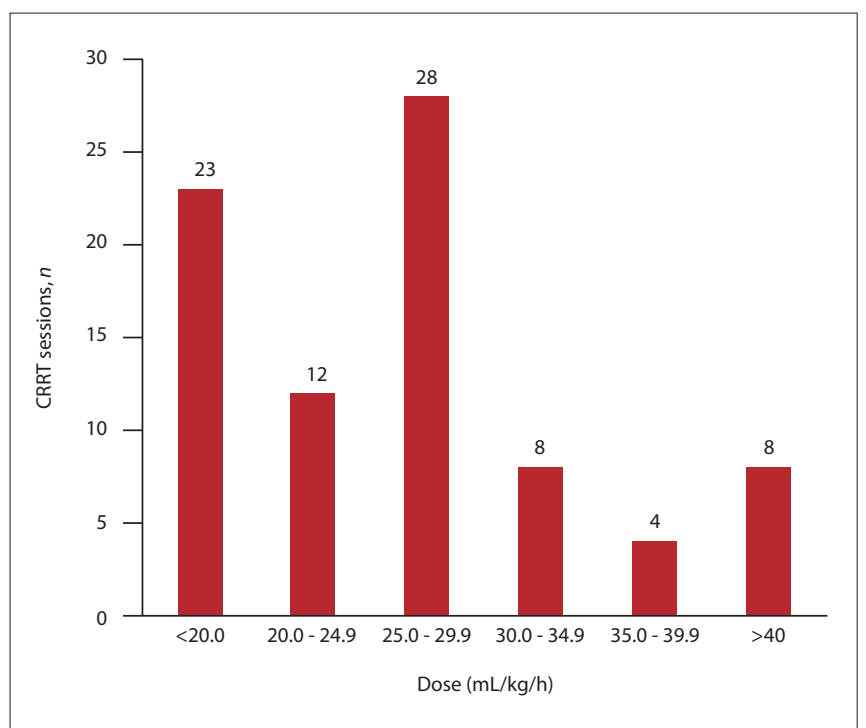

Fig. 2. Dose range of CRRT in quantiles. (CRRT = continuous renal replacement therapy.)

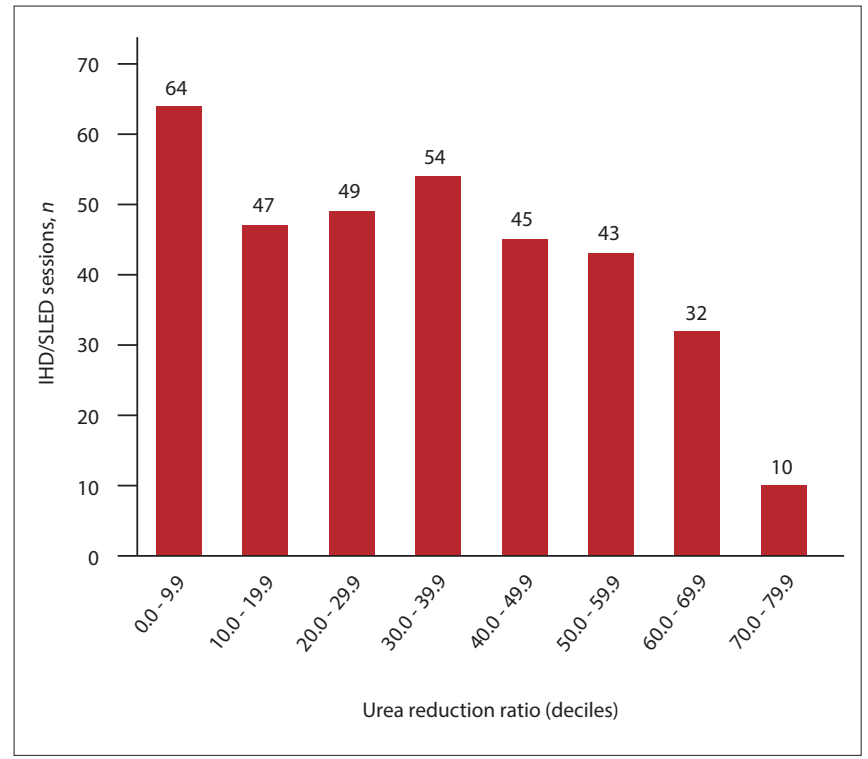

Fig. 3. Urea reduction ration per individual IHD/SLED session. (IHD = intermittent haemodialysis; SLED = slow low-efficiency dialys. $)$

The median URR and CRRT dose were not statistically different between the patients who survived or died $(p=0.233$ and $p=0.956$, respectively). There was no statistically significant difference in admission biochemistry between survivors and non-survivors. Sepsis was a strong marker for mortality ( $n=26 / 40$ v. $n=26 / 68$; $p=0.01$ ) There was no difference in the median URR or CRRT dose in survivors v. nonsurvivors ( $p=0.233$ and $p=0.956$, respectively)

\section{Discussion}

In a heterogenous ICU population in KwaZulu-Natal, SA, the patient population consisted of predominantly young males, which is consistent with findings from other studies in SA. ${ }^{[4,10]}$ The most common indication for initiating RRT was an increasing serum urea and creatinine levels. There were multiple indications for dialysis in the majority of patients studied. As expected, we found that AKI is a heterogenous disease in critically ill patients. The top four indications for RRT (high serum creatinine, urea, acidosis and control of fluid

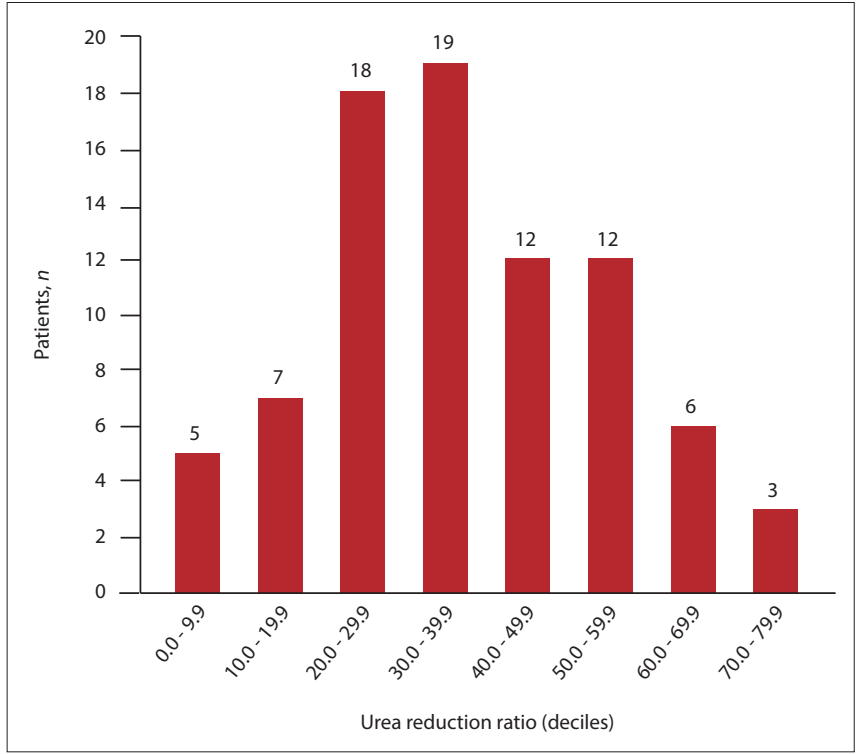

Fig. 4. Median urea reduction ratio per patient.

Table 6. Pre- and post-dialysis administration of potential nephrotoxins

\begin{tabular}{lll}
\hline Potential nephrotoxin & Pre-dialysis & Post-dialysis \\
\hline Furosemide & 28 & 6 \\
Aminoglycoside & 20 & 9 \\
Amphotericin B & 3 & 5 \\
NSAIDs & 1 & 0 \\
Vancomycin & 7 & 6 \\
NSAIDS = non-steroidal anti-inflammatory drugs. &
\end{tabular}

balance) reflect the complex decision-making often required when initiating RRT in critically ill patients. Similar studies in sub-Saharan Africa have also looked at indications for RRT and found that the median number of indications for RRT in AKI is between one and three. ${ }^{[3]}$

The secondary outcomes describing the methods of RRT show a varied practice among critical care practitioners. IHD/SLED and CRRT modalities are used according to the available resources in the various units in this study. The high use of IHD/SLED in critically ill patients may be a surprising finding, especially to readers from developed countries where continuous veno-venous haemodiafiltration is generally the preferred modality for critically ill patients with AKI. There is currently no superiority of any particular mode of haemodialysis for patients with an acute need for RRT with AKI. ${ }^{[1,12]}$ There is some evidence emerging that there may be greater long-term freedom from RRT in CRRT as compared with SLED/IHD. ${ }^{[13,14]}$ In our setting, access to CRRT is limited by the availability of machines capable of this technique and the availability of trained staff to operate these machines. Therefore, the use of IHD/ SLED is appropriate. The current consensus for dosing of CRRT is $20-25 \mathrm{~mL} / \mathrm{kg} / \mathrm{h}$ as a delivered minimum dose and there is little benefit gained from increasing the dose beyond this point. ${ }^{[8,15-17]}$ Previous studies have shown that not all patients achieve the prescribed dose, with only $68-89 \%$ achieving the desired goal. ${ }^{[18,19]}$ Our study shows a variable result in this regard, with a number of patients receiving both lower and higher doses of CRRT than the recommended dose. More than a quarter of patients received less 
than the recommended minimum dose of CRRT. This may reflect a lack of standardised protocols for CRRT dosing in the units studied or inadvertent underdosing. The literature describes low-dose CRRT as $<20 \mathrm{~mL} / \mathrm{kg} / \mathrm{h} .{ }^{[20]}$ An observational study by Fujii et al. ${ }^{[21]}$ showed no significant differences in outcomes with lower doses than $20 \mathrm{~mL} / \mathrm{kg} / \mathrm{h}$ in CRRT. Our study was not designed primarily to investigate the differences in dosing, so further work is required to delineate this finding and its clinical implications. The dose of RRT needs to be individualised to the patient and the indication for the prescription. Careful attention needs to be paid to the dose of RRT and, if necessary, altered appropriately.

The urea clearance was poor in the majority of patients who received IHD/SLED. There are a few possibilities for this finding. Urea is produced as a result of protein breakdown and this can be variable in critically ill patients. We did not include data for the protein intake of these patients, which is a confounder. There may also be a lack of awareness of the need for individualised prescriptions for critically ill patients requiring RRT.

The association between sepsis-associated AKI and death is not surprising. There is a high burden of infectious disease in developing countries, with a high burden of sepsis and septic shock in the ICUs studied. This has been reported in other studies on AKI in sub-Saharan Africa. ${ }^{[2-4]}$

The high rate of nephrotoxin administration was a surprising finding. The current guidelines recommend limiting nephrotoxin administration in patients with AKI. ${ }^{[8]}$ Amphotericin B is a known nephrotoxin but the availability of echinocandin therapy is limited in SA public hospitals and may account for the administration of this drug both pre- and postdialysis. Septic shock is often treated with dual antimicrobial therapy in a number of ICUs in SA. This may account for the high rate of aminoglycoside administration as an alternative that is less nephrotoxic.

Although there was a high rate of renal recovery, at least 25 patients required ongoing RRT on discharge from the ICU. This represents a burden on the nephrology and medical services outside of the ICU, which may have their own criteria for RRT that need to be considered. This highlights the importance of the need for continuity of care within the public hospital sector, and collaboration between intensive care and nephrology services is essential to ensure that patient therapy is not compromised.

\section{Study limitations and strengths}

Patient weight was estimated according to patient height and visual estimation because not all the ICUs had bed scales. This may have led to errors in the estimation of dosing the RRT. However, this situation is unlikely to change in the context of developing countries and thus represents a real-life scenario.

The timing of the repeat serum urea was not standardised in each unit, which may have resulted in either over- or underestimation of the URR. Individual RRT prescriptions were at the discretion of the treating clinician and factors other than planned URR or volume removal may have influenced the specific dosing. The use of URR is considered interchangeable with the traditional use of the dialyser clearance $\times$ dialysis time/volume of distribution of urea $(K t / V)$ equation for calculation of renal dosing in long-term dialysis patients. However, there may be some differences between URR and $K t / V$, as URR is not directly linked to body size and does not account directly for convective urea losses. ${ }^{[9]}$ Most guidelines endorse the use of a measurement as a marker of dialysis efficiency and we selected URR due to its ease of clinical use and calculation. There is a potential for the Hawthorne effect (more attention being paid to the intervention being studied), as clinicians became more aware of dosing calculations for RRT during the study. However, despite this potential, the adequacy of dosing was still inadequate in the majority of patients studied.

The strengths of the study include that it is a prospective, multicentre observational study, which ensures timeous and accurate data collection with few missing data. A number of different dialysis machines were used, and a number of different intensivists involved in the decision to initiate RRT, which lends to external validity of the study.

\section{Conclusion}

The most common reasons for initiating RRT were a high or increasing urea and creatinine, and patients often had multiple indications $(>3)$ for initiation of RRT. This reflects the complex decision-making that is undertaken to initiate RRT. The dosing of RRT was not optimal, with a wide range shown in CRRT, and the majority of patients did not achieve a URR $>65 \%$. We hope this study stimulates discussion and collaboration to develop a clear set of national guidelines in line with international recommendations, taking into account the challenges faced by critical care clinicians locally that pertain to the rational use and dosing of RRT in critical care in southern Africa. Training is required to raise awareness of dosing of dialysis and the need for individualised dosing prescriptions for patients. Further collaborative research is required in southern Africa to delineate the challenges faced by other clinicians in the allocation and use of RRT.

\section{Declaration. None.}

\section{Acknowledgements. None.}

Author contributions. DLS and KdV conceptualised and designed the study. DLS, KdV, RW, TK, MF, TH and DJJM collected the data, and DLS and $\mathrm{KdV}$ performed data analyses. All authors were involved in writing and approving the manuscript for publication.

\section{Funding. None.}

Conflicts of interest. None.

. Obrador GT, Rubilar X, Agazzi E, Estefan J. The challenge of providing renal replacement therapy in developing countries: The Latin American perspective. Am J Kidney Dis 2016;67(3):499-506. https://doi.org/10.1053/j.ajkd.2015.08.033

2. Evans RD, Hemmila U, Craik A, et al. Incidence, aetiology and outcome of communityacquired acute kidney injury in medical admissions in Malawi. BMC Nephrol 2017;18(1):21. https://doi.org/10.1186/s12882-017-0446-4

3. Olowu WA, Niang A, Osafo C, et al. Outcomes of acute kidney injury in children and adults in sub-Saharan Africa: A systematic review. Lancet Glob Health 2016;4(4):e242-250. https://doi. org/10.1016/S2214-109X(15)00322-8

4. Dlamini TAL, Heering PJ, Chivese T, Rayner B. A prospective study of the demographics, management and outcome of patients with acute kidney injury in Cape Town, South Africa. PLoS ONE 2017;12(6):e0177460. https://doi.org/10.1371/journal.pone.0177460

5. Skinner DL, Hardcastle TC, Rodseth RN, Muckart DJ. The incidence and outcomes of acute kidney injury among patients admitted to a level I trauma unit. Injury 2014;45(1):259-264. https://doi.org/10.1016/j.injury.2013.07.013

6. Boswell MT, Rossouw TM. Approach to acute kidney injury in HIV-infected patients in South Africa. South Afr J HIV Med 2017;18(1):714. https://doi.org/10.4102/sajhivmed.v18i1.714

7. Sidley P. South African row over denial of dialysis. BMJ 1997;315(7122):1562. https://doi.org/ $10.1136 \% 2 \mathrm{Fbmj} .315 .7122 .1559 \mathrm{~h}$

8. Khwaja A. KDIGO clinical practice guidelines for acute kidney injury. Nephron Clin Pract 2012;120(4):c179-184. https://doi.org/10.1159/000339789

9. Liang KV, Zhang JH, Palevsky PM. Urea reduction ratio may be a simpler approach for measurement of adequacy of intermittent hemodialysis in acute kidney injury. BMC Nephrol 2019;20(1):82. https://doi.org/10.1186/s12882-019-1272-7

10. Parker A, Lahri S, Taljaard JJ, Koegelenberg CFN. HIV-positive patients in the intensive care unit. S Afr Med J 2017;107(11):12118. https://doi.org/10.7196\%2FSAMJ.2017.v107i11.12907

11. Zhang L, Yang J, Eastwood GM, Zhu G, Tanaka A, Bellomo R. Extended daily dialysis v. continuous renal replacement therapy for acute didney injury: A meta-analysis. Am J Kidney Dis 2015;66(2):322-330. https://doi.org/10.1053/j.ajkd.2015.02.328

12. Nash DM, Przech S, Wald R, O'Reilly D. Systematic review and meta-analysis of renal replacement therapy modalities for acute kidney injury in the intensive care unit. J Crit Care 2017;41:138-144. https://doi.org/10.1016/j.jcrc.2017.05.002 


\section{RESEARCH}

13. Wald R, Shariff SZ, Adhikari NK, et al. The association between renal replacement therapy modality and long-term outcomes among critically ill adults with acute kidney injury: A retrospective cohort study. Crit Care Med 2014;42(4):868-877. https://doi.org/10.1097/ccm.0000000000000042

14. Bell M, SWING, Granath F, Schon S, Ekbom A, Martling CR. Continuous renal replacement therapy is associated with less chronic renal failure than intermittent haemodialysis after acute renal failure. Intensive Care Med 2007;33(5):773-780. https://doi.org/10.1007/s00134-007-0590-6

15. Palevsky PM, Zhang JH, O'Connor TZ, et al. Intensity of renal support in critically ill patients with acute kidney injury. N Engl J Med 2008;359(1):7-20. https://doi.org/10.1056/nejmoa0802639

16. Bellomo R, Cass A, Cole L, et al. An observational study fluid balance and patient outcomes in the randomised evaluation of normal v. augmented level of replacement therapy trial. Crit Care Med 2012;40(6):1753-1760. https://doi.org/10.1097/ccm.0b013e318246b9c6

17. Prowle JR, Schneider A, Bellomo R. Clinical review: Optimal dose of continuous renal replacement therapy in acute kidney injury. Crit Care 2011;15(2):207. https://doi.org/10.1186\%2Fcc9415

18. Evanson JA, Himmelfarb J, Wingard R, et al. Prescribed v. delivered dialysis in acute renal failure patients. Am J Kidney Dis 1998;32(5):731-738. https://doi.org/10.1016/s02726386(98)70127-1
19. Vesconi S, Cruz DN, Fumagalli R, et al. Delivered dose of renal replacement therapy and mortality in critically ill patients with acute kidney injury. Crit Care 2009;13(2):R57. https://doi. org/10.1186/cc7784

20. Li P, Qu LP, Qi D, et al. High-dose v. low-dose haemofiltration for the treatment of critically ill patients with acute kidney injury: An updated systematic review and meta-analysis. BMJ Open 2017;7(10):e014171. https://doi.org/10.1136/bmjopen-2016-01417

21. Fujii T, Namba Y, Fujitani S, et al. Low-dose continuous renal replacement therapy for acute kidney injury. Int J Artif Organs 2012;35(7):525-530. https://doi.org/10.5301/ijao.5000110

Accepted 12 November 2020. 